\title{
Characterisation of Concurrent Multiband RF Transceiver for WLAN Applications
}

\author{
Brijesh Iyer
}

Department of E\& TC Engineering

Dr. B A Technological University, Maharashtra-India-40213

brijeshiyer [at] dbatu.ac.in

\begin{abstract}
This paper reports design of a multiband RF transceiver for simultaneous operation at $2.44 \mathrm{GHz}$ and 5.25 GHZ. The specific choice of the frequency is to meet the WLAN applications. The basic aim of the proposed design is to reduce the component count, to achieve power saving with a compact size. The proposed transceiver is devised by using indigenously deigned dualband circuits and off the self-laboratory equipment's. The entire transmitter structure is implemented using hybrid microwave integrated circuit (HMIC). The proposed multiband transceiver exhibits a link budget of $-64 \mathrm{dBm}$ and link margin of $74 \mathrm{dBm}$, the implemented transceiver exhibits an EMR of $1.5 \times 10^{-7}$ for concurrent dual-standard WLAN application. Hence, the proposed transceiver is efficient as well as safe for the human operation.
\end{abstract}

\section{Keywords: Dual-band transmitter; Concurrent, Transmitter, Surface mount technology (SMT),WLAN}

\section{Introduction}

The last decade witnessed initiation of massive applications in WLAN. With the growing demand of user, it becomes the need of hour that the front end circuit design must support more than one application simultaneously. This requirement may be accomplished by the use of multiband architecture of front end circuits. A multiband architecture can be achieved by parallel, switchable or concurrent arrangement of transceiver building blocks. Use of parallel system architecture for concurrent operation at individual frequency band is less attractive due to the requirements for high power consumption, large hardware and bulky nature. A switched mode multiband system has a drawback of inconsistent measurement conditions due to switching operation while operating at a particular band [1]. However, all these schemes are not commercially viable due to one or more reasons like the requirement of a large hardware, high power consumption, and complex radio architecture.

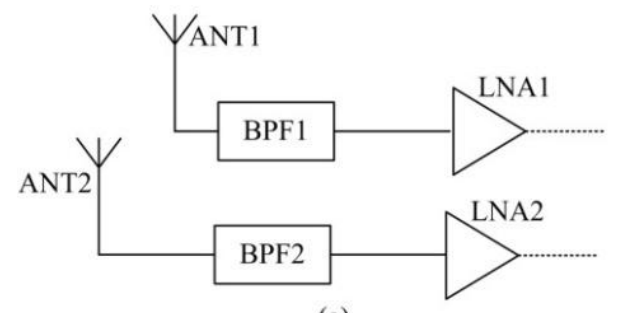

(a)
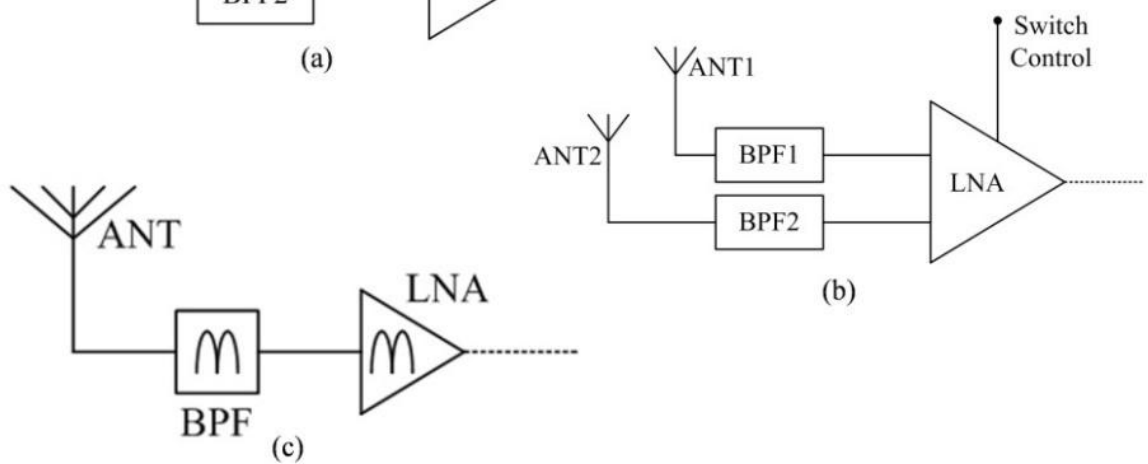

(b)

Fig.1. Taxonomy of radio frontend design: (a) Parallel architecture; (b) Switchable architecture; (c) Concurrent architecture

B. Iyer, S. Nalbalwar and R. Pawade (Eds.)

ICCASP/ICMMD-2016. Advances in Intelligent Systems Research.

Vol. 137, Pp. 834-846.

(C) 2017- The authors. Published by Atlantis Press

This is an open access article under the CC BY-NC license (http://creativecommons.org/licens)es/by-nc/4). 
The current trend in the area of millimeterwave circuit design is to reduce the component count, to achieve compact size and to reduce the circuit size. Fig.1 depicts the taxonomy of radio frontend design to achieve concurrent operation. The current trend in the area of Microwave / Millimeter wave integrated circuit research is to reduce system losses, increase compactness and reduce the power consumption level so that the RF systems can be used as a portable handheld device. A concurrent multiband system, based on hardware sharing, fulfils all above criteria. Hence, the present work is motivated to provide a viable solution to bridge the gap between the compact size, low cost and power consumption and multiband operation.

The proposed RF transceiver concurrently operates at $2.44 \mathrm{GHz}$ and $5.25 \mathrm{GHz}$ band. Fig. 2 shows the conceptual block diagram of a concurrent multiband RF transceiver.

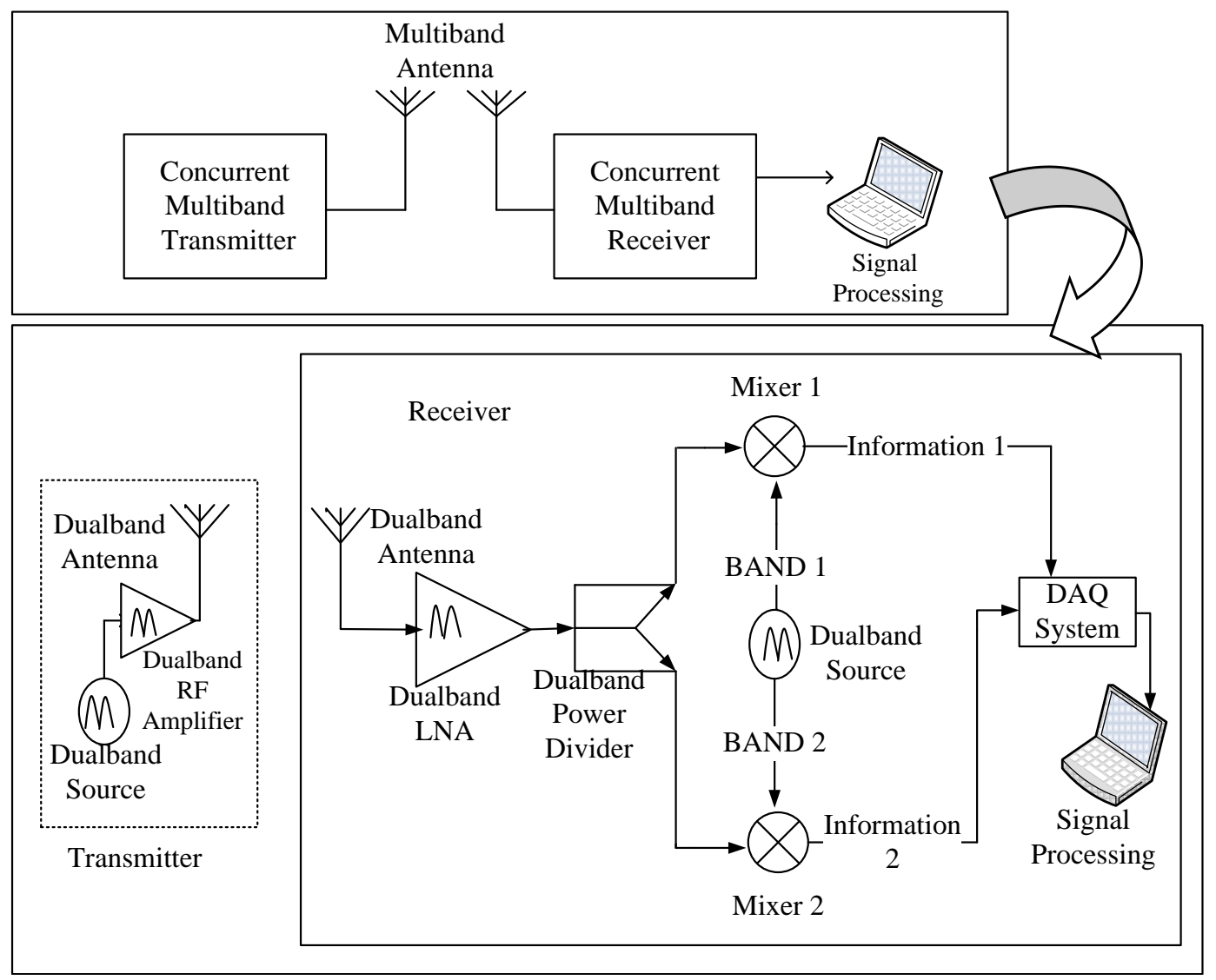

Fig. 2. Conceptual block diagram of the proposed multiband transceiver.

Section 2 and 3 of the paper describes the transmitter section and the receiver section respectively. The system level analysis of the proposed transceiver is given in section 4 . The conclusion and future scope of the proposed work is discussed in section 5 .

\section{The Transmitter}

The transmitter section of the proposed dualband transceiver consist of indigenously designed dualband antenna \& Wilkinson's power divider(WPD), $2.44 \mathrm{GH}$ and $5.25 \mathrm{GHz}$ oscillators and a power amplifier to operated at the designated frequencies.

\subsection{Dualband Antenna}

In this analysis three concurrent dualband microstrip patch antenna array is used for the analysis purpose. The particular choice is owing to the fact that it has low cost, light weight and ease in fabrication. All these antenna structure operates simultaneously at $2.44 \mathrm{GHz}$ and $5.25 \mathrm{GHz}$ band [2-4]. Fig. 3 shows the fabricated prototype of the antenna used for the analysis purpose. 


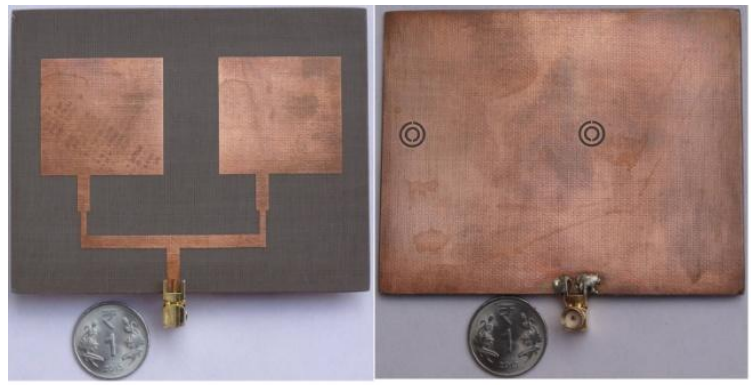

(a)

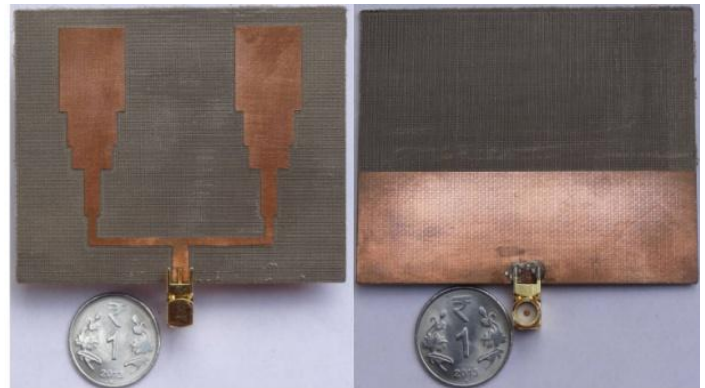

(b)

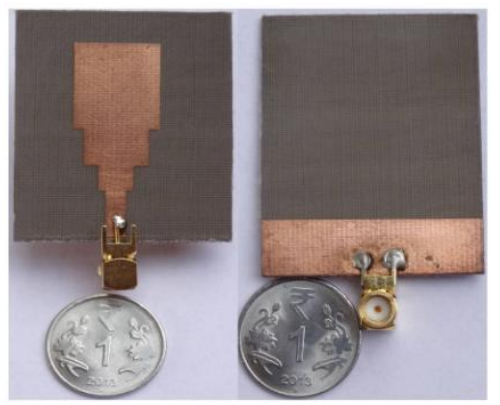

(c)

Fig. 3. Fabricated prototype of $2.44 \mathrm{GHz}$ and $5.25 \mathrm{GHz}$ concurrent dualband antenna: (a) Directive antenna array; (b) Omnidirective antenna array and (c) Single patch omnidirective antenna.

The performance of these antennas in terms of gain and bandwidth is given in Table 1. Form the comparison it is evidenced that the selected designs excels in the individual class applications.

Table 1. Performance Comparison of the antenna prototype

\begin{tabular}{|l|c|c|c|c|c|}
\hline \multirow{2}{*}{ Performance } & \multicolumn{2}{|c|}{ Gain(dBi) } & \multicolumn{2}{c|}{ Bandwidth (MHz) } & Dimensions \\
\cline { 2 - 5 } & At 2.44 GHz & At 5.25 GHz & At 2.44 GHz & At 5.25 GHz & \{LxW (mm) \\
\hline$[2]$ & 2.2 & 3.1 & 760 & 720 & $35 \times 45$ \\
\hline$[3]$ & 5.0 & 4.75 & 780 & 760 & $60 \times 79$ \\
\hline$[4]^{*}$ & 7.21 & 8.12 & 120 & 90 & $78 \times 97$ \\
\hline
\end{tabular}

* Directive antenna

\subsection{The Wilkinson's Power Divider/Combiner}

The circuit topology of Wilkinson's Power Divider (WPD) in [5] is modified according to the frequency ratio of 2.44/5 .25 GHz i.e. 2.15 for the proposed design. A key shaped compact WPD is used for this analysis. It is designed using microstrip technology on a NH9320 substrate. The validation of the proposed topology is carried out with Agilent advanced design system (ADS) platform. Fig. 4 shows the fabricated prototype of WPD.

A polygon conductor is used to connect ' $\mathrm{ZA}$ ' and ' $\mathrm{ZB}$ ' with length of $4.2 \mathrm{~mm}$ at an angle of $45^{\circ}$ with horizontal axis. The angle between microstrip lines of ' $\mathrm{ZA}$ ' and ' Zoc ' is $30^{\circ}$. The isolation between port 2 and port 3 is obtained by connecting a $100 \Omega$ resistor. Due to the modification in the circuit topology and use of polygon conductors and tapers, the dimensions are further optimized to meet the frequency ratio requirement along with compact size, better return and insertion loss with isolation on both bands. Table 2 summarizes the dimensions of the proposed WPD with empirical relations along with the optimized dimensions of the proposed structure. The length of open stub and 'ZB ' are further miniaturized by meandering.

The measured gain performance of WPD is summarised in Table 3. Further the capacity of the designed WPD is verified by providing a $10 \mathrm{dBm}$ power at port 1 . Here two independent signal source (R\&S SMR20: $10 \mathrm{MHz}$ to 20GHz and Agilent ES257D PSG: $100 \mathrm{kHz}$ to 20GHz) are used at two designated bands. The WPD is connected to the source via a cable and connector. The power level is measured with the help of a power meter (R\&S NRVS 1020). Table 4 provides the capacity of the proposed prototype as a power divider. 

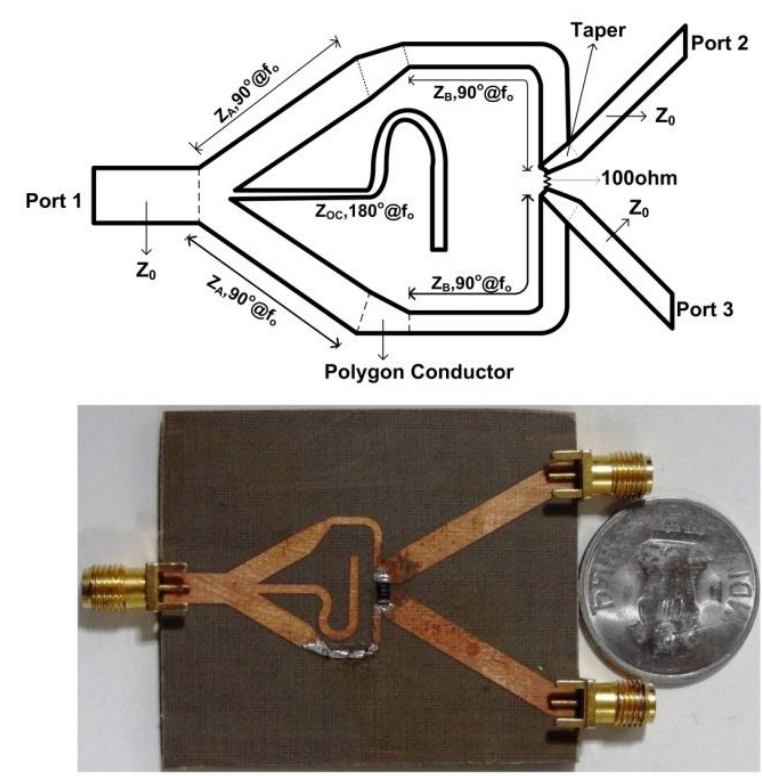

Fig. 4. 2.44/5.25 GHz Concurrent dualband WPD

Table 2. WPD Dimensions

\begin{tabular}{|c|c|c|c|c|}
\hline \multirow{3}{*}{$\begin{array}{l}\text { Impedance } \\
(\Omega)\end{array}$} & \multicolumn{4}{|c|}{ Dimension } \\
\hline & \multicolumn{2}{|c|}{ With empirical relations } & \multicolumn{2}{|c|}{ After optimization } \\
\hline & $\mathbf{L}(\mathbf{m m})$ & $\mathbf{W}(\mathbf{m m})$ & $\mathbf{L}(\mathbf{m m})$ & $\mathbf{W}(\mathbf{m m})$ \\
\hline $\mathrm{Z}_{\mathrm{A}}=45.72$ & 12 & 4.2 & 12 & 3 \\
\hline $\mathrm{Z}_{\mathrm{B}}=109.36$ & 12.78 & 0.74 & 12.78 & 0.9 \\
\hline $\mathrm{Z}_{\mathrm{OC}}=56.44$ & 24.40 & 3 & 28.80 & 1.02 \\
\hline
\end{tabular}

Table 3. Measured Gain Performance of WPD

\begin{tabular}{|l|c|c|c|}
\hline $\begin{array}{l}\text { Frequency } \\
\text { (GHz) }\end{array}$ & $\begin{array}{l}\text { Return loss } \\
\text { (S11 dB) }\end{array}$ & $\begin{array}{l}\text { Insertion Loss } \\
(\mathbf{S 2 1} \text { dB) }\end{array}$ & $\begin{array}{l}\text { Isolation } \\
(\mathbf{d B})\end{array}$ \\
\hline 2.44 & -9 & -3 & -17 \\
\hline 5.25 & -8 & -4.3 & -15 \\
\hline
\end{tabular}

Table 4. Measured Gain Performance of WPD

\begin{tabular}{|l|c|c|c|}
\hline $\begin{array}{l}\text { Frequency } \\
\text { (GHz) }\end{array}$ & $\begin{array}{l}\text { Input power at } \\
\text { port 1(dBm) }\end{array}$ & $\begin{array}{l}\text { Output power at } \\
\text { port 2(dBm) }\end{array}$ & $\begin{array}{l}\text { Output power at } \\
\text { port 3(dBm) }\end{array}$ \\
\hline 2.44 & 9.02 & 5.83 & 5.94 \\
\hline 5.25 & 8.06 & 4.3 & 4.45 \\
\hline
\end{tabular}

Further, the capacity of WPD as a concurrent power combiner (WPC) is validated by providing $8.8 \mathrm{dBm}$ input power at port 2 with $2.44 \mathrm{GHz}$ and $8 \mathrm{dBm}$ of input power at port 3 with $5.25 \mathrm{GHz}$ via cables and connectors. Variations in the supplied power at individual ports are due to the losses incurred by cables and connectors. A $9.20 \mathrm{dBm}$ power is obtained at port 1 which clearly indicates that proposed WPD can be used as a power combiner for concurrent dualband operation.

\subsection{The Oscillators}

To cater the need of a source, two oscillators are designed to operate at $2.44 \mathrm{GHz}$ and $5.25 \mathrm{GHz}$. A Si-doped AIGaAs FET NE4210S01 is selected for this design since its operating frequency is from $2 \mathrm{GHz}$ to $18 \mathrm{GHz}$. DC Bias simulation is performed in ADS using the transistor model. DC bias point for oscillator design was selected as VDS $=2 \mathrm{~V}$ and IDS $=10 \mathrm{~mA}$ and $\mathrm{VGS}=0.69 \mathrm{~V}$. A microstrip line biasing circuitry is selected for the DC bias NE4210S01. Fig. 5 shows a microstripline bias network. 


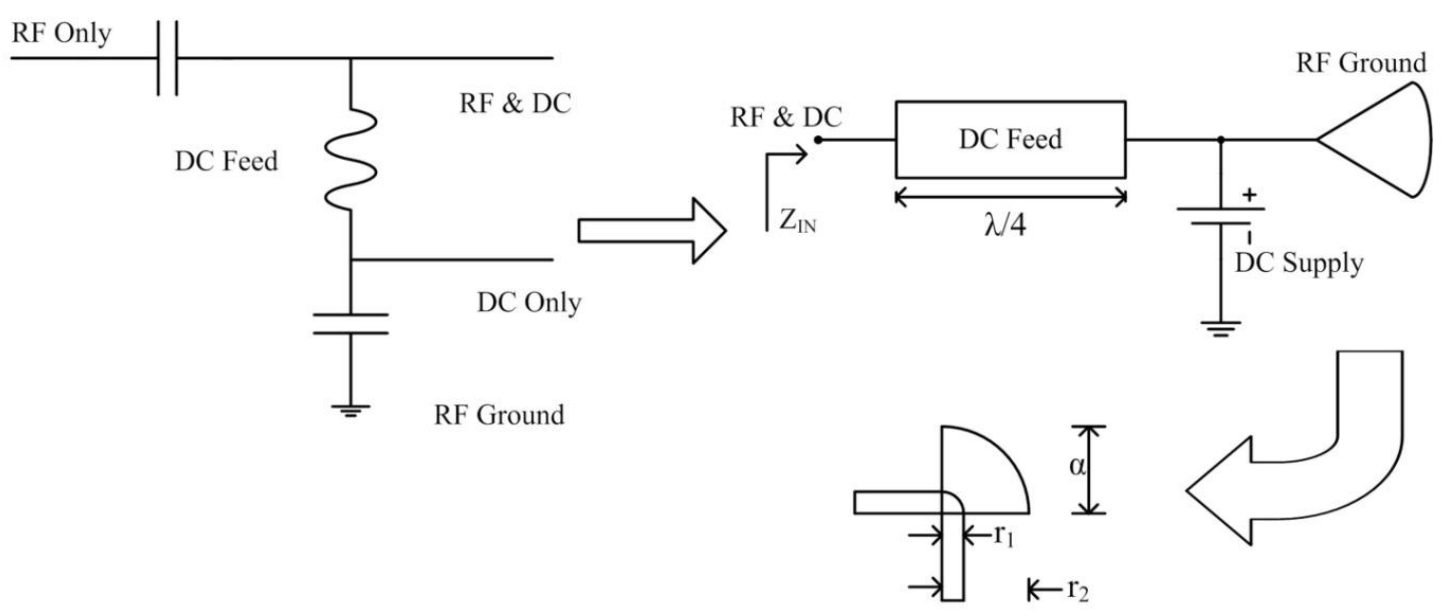

Fig. 5. Microstripline bias network.

In microstrip implementation, the inductor may be substituted by a high impedance line and the capacitor can be realized as an open or a radial stub. A radial stub is used to provide a broadly resonant RF short circuit. When cascaded with high impedance quarter wavelength transmission lines the radial stub provides an effective decoupling network for microwave amplifiers and other active components [6]. The high impedance (selected as 130) quarter wavelength (with electrical length 900) microstrip line is followed by a radial stub. The dimensions are calculated using 'line calc' tool in ADS. The bias network design is similar for $2.44 \mathrm{GHz}$ and $5.25 \mathrm{GHz}$, band except for the variation in the dimensions. Table 5 and 6 provides the dimensions of the bias network and radial stub respectively.

Table 5. Dimensions for bias network

\begin{tabular}{|c|c|c|c|}
\hline $\mathbf{Z}_{\mathbf{O}}(\mathbf{\Omega})$ & Frequency $(\mathbf{G H z})$ & $\mathbf{W}(\mathbf{m m})$ & $\mathbf{L}(\mathbf{m m})$ \\
\hline \multirow{2}{*}{130} & 2.44 & \multirow{2}{*}{0.43} & 20.39 \\
\cline { 2 - 2 } & 5.25 & & 9.44 \\
\hline
\end{tabular}

Table 6. Dimensions for radial stub

\begin{tabular}{|c|c|l|c|}
\hline Frequency $(\mathbf{G H z})$ & $\mathbf{r}_{\mathbf{1}}(\mathbf{m m})$ & $\mathbf{r}_{\mathbf{2}}(\mathbf{m m})$ & $\boldsymbol{\alpha}($ degree $)$ \\
\hline 2.44 & \multirow{2}{*}{0.43} & 12.89 & \multirow{2}{*}{60} \\
\cline { 1 - 1 } 5.25 & & 6.86 & \\
\hline
\end{tabular}

S-Parameter simulation is performed with the DC bias network. Table 7 provides the S-parameters for the proposed oscillator design. Using the S-Parameters, transistor's stability is analyzed at the two design frequencies with the help of $\mathrm{K}-\Delta$ and $\mu$ test.

Table 7. S-parameters of NE4210S01 transistor

\begin{tabular}{|l|l|l|l|l|}
\hline $\begin{array}{l}\text { Frequency } \\
(\mathbf{G H z})\end{array}$ & $\mathbf{S}_{\mathbf{1 1}}$ & $\mathbf{S}_{\mathbf{1 2}}$ & $\mathbf{S}_{\mathbf{2 1}}$ & $\mathbf{S}_{\mathbf{2 2}}$ \\
\hline 2.44 & $1.20 \angle-8.20^{\circ}$ & $0.07 \angle 83.81^{\circ}$ & $2.31 \angle-128.84^{\circ}$ & $1.11 \angle-14.79^{\circ}$ \\
\hline 5.25 & $1.96 \angle-48.89^{\circ}$ & $0.25 \angle 50.71^{\circ}$ & $6.81 \angle 168.06^{\circ}$ & $1.49 \angle-54.86^{\circ}$ \\
\hline
\end{tabular}

Table 8. Stability analysis of NE4210S01 transistor

\begin{tabular}{|c|c|c|c|c|}
\hline $\begin{array}{l}\text { Frequency } \\
(\mathbf{G H z})\end{array}$ & $\boldsymbol{\Delta}$ & $\mathbf{K}$ & $\boldsymbol{\mu}$ & $\boldsymbol{\mu}_{\text {prime }}$ \\
\hline 2.44 & 1.184 & -0.847 & -0.921 & -0.779 \\
\hline 5.25 & 1.866 & -0.452 & -0.657 & -0.363 \\
\hline
\end{tabular}


Table 9: Dimensions of the matching network

\begin{tabular}{|c|c|c|c|c|c|c|}
\hline $\begin{array}{c}\text { Frequency } \\
(\mathrm{GHz})\end{array}$ & $\mathrm{Z}_{\mathrm{O}}$ & Effect & $\begin{array}{c}\text { Electrical } \\
\text { Length }\end{array}$ & $\begin{array}{c}\text { Width } \\
(\mathrm{mm})\end{array}$ & $\begin{array}{c}\text { Length } \\
(\mathrm{mm})\end{array}$ & $\begin{array}{c}\text { Optimised } \\
\text { Length }(\mathrm{mm})\end{array}$ \\
\hline \multirow{2}{*}{2.44} & \multirow{3}{*}{$50 \Omega$} & Inductive & $84.480^{\circ}$ & \multirow{2}{*}{3.64} & 18.05 & 10.12 \\
\cline { 3 - 4 } \cline { 6 - 7 } & Capacitive & $103.610^{\circ}$ & & 22.05 & 21.38 \\
\cline { 3 - 7 } & Inductive & $93.502^{\circ}$ & \multirow{2}{*}{3.68} & 9.16 & 5.92 \\
\cline { 3 - 4 } \cline { 6 - 7 } & & Capacitive & $118.920^{\circ}$ & & 11.66 & 15 \\
\hline
\end{tabular}

Based on the S-parameters, an impedance matching network design is initiated. Using line calc tool and reflection coefficients for the transistor, a microstripline matching network is designed. Table 9 summarises the matching network configuration. Further, resonator is designed using the empirical relationship and is summarised in Table 10.

Table 10: Details of resonator design

\begin{tabular}{|l|l|l|}
\hline Parameter & $2.44 \mathrm{GHz}$ & $5.25 \mathrm{GHz}$ \\
\hline $\mathrm{Z}_{\mathrm{IN}}(\Omega)$ & $-43.912-j 260.9$ & $-23.296-j 107.945$ \\
\hline $\mathrm{Z}_{\mathrm{L}}(\Omega)$ & $14.637+j 260.9$ & $7.765+j 107.945$ \\
\hline Electrical Length & $169.15^{\circ}$ & $155.146^{\circ}$ \\
\hline Physical Length $(\mathrm{mm})$ & 36 & 15.65 \\
\hline Physical Width $(\mathrm{mm})$ & 3.64 & 3.68 \\
\hline Optimised Length $(\mathrm{mm})$ & 33 & 9 \\
\hline
\end{tabular}

Based on these analyses, a fabricated prototype of the proposed oscillators is devised. Further, measurement of these oscillators is carried out with Agilent Filedfox Spectrum Analyzer (100 MHz to $6 \mathrm{GHz}$ ). Fig. 6 depicts the measurement setup and the fabricated prototypes of the proposed oscillators. The measured power spectrum of the oscillators is depicted in Fig.7.

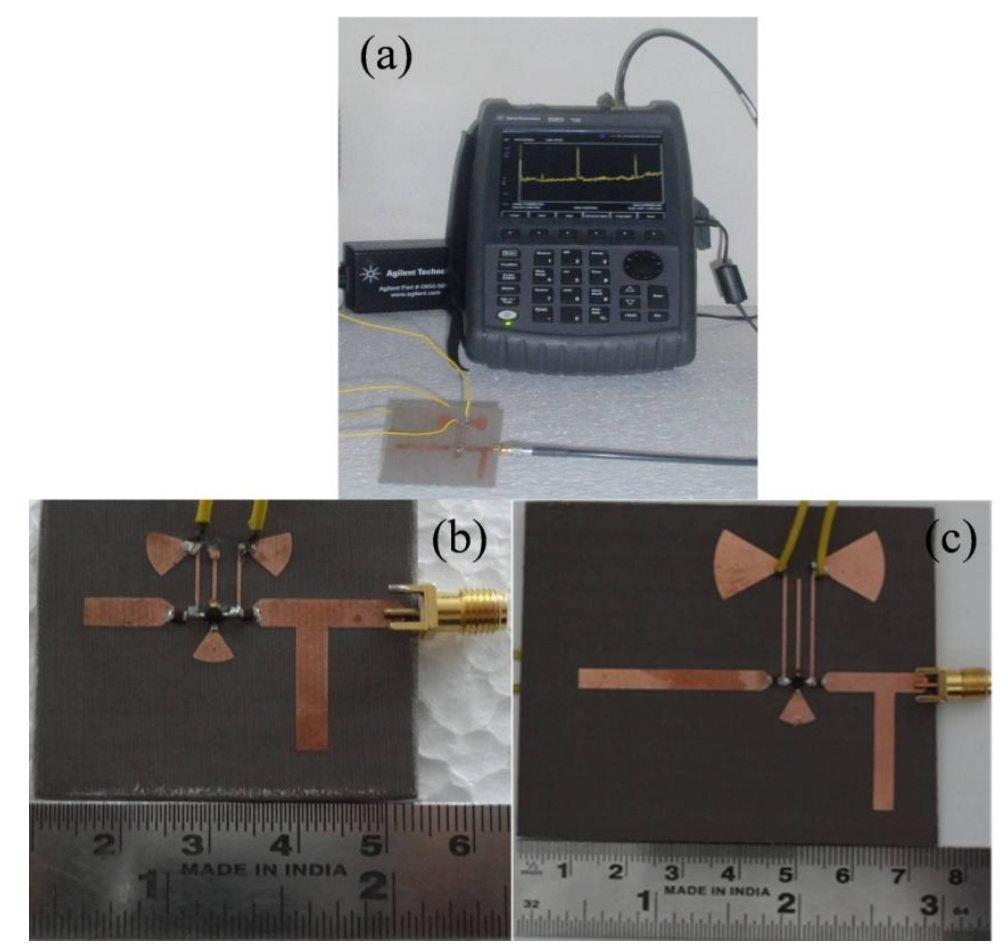

Fig. 6. (a) Measurement setup and the fabricated prototypes of the proposed oscillators at (b) $5.25 \mathrm{GHz}$; (c) $2.44 \mathrm{GHz}$. 

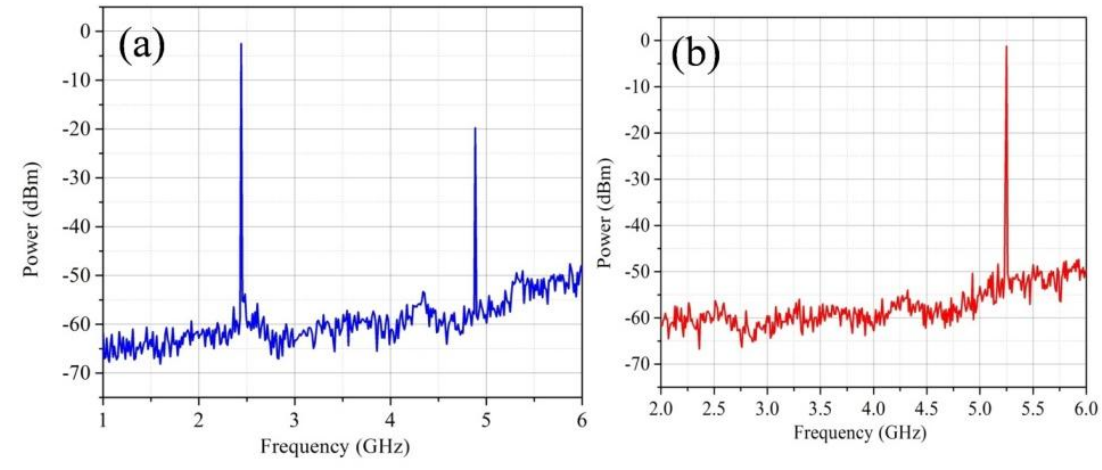

Fig. 7. Measurement power spectrum at: (a) $2.44 \mathrm{GHz}$ (b) $5.25 \mathrm{GHz}$

The phase noise of the oscillators had been calculated by using the relation [6]:

$$
P_{\text {NOISE }}=P_{S B}-P_{C}-10 \log _{10}(R B W) d B C
$$

where $P_{S B}=$ Sideband power in $\mathrm{dB}$ at an offset of $100 \mathrm{KHz}, P_{C}=$ Carrier Power in $\mathrm{dB}$; and $R B W=$ Resolution bandwidth of the spectrum analyzer in MHz. Considering the losses incurred due to the measurement setup and tolerance of the fabrication process, the carrier power is assumed to be $0 \mathrm{dBm}$ along with a $R B W$ of $200 \mathrm{MHz}$. Table 11 summarizes the simulated and measured phase noise of the oscillators at $2.44 \mathrm{GHz}$ and $5.25 \mathrm{GHz}$.

Table 11: Phase noise calculation

\begin{tabular}{|l|l|l|l|}
\hline $\begin{array}{l}\text { Frequency } \\
(G H z)\end{array}$ & $P S B d B$ & $\begin{array}{l}\text { Simulated phase } \\
\text { noise }(d B c)\end{array}$ & $\begin{array}{l}\text { Measured phase } \\
\text { noise }(d B c)\end{array}$ \\
\hline 2.44 & -46 & -177.7 & -109 \\
\hline 5.25 & -43 & -182.1 & -106 \\
\hline
\end{tabular}

\subsection{The Power Amplifier}

Commercial IC GaLi-24 $4^{+}$is used as a power amplifier (PA) in this analysis. It is a surface mount device (SMD) and operates between DC to $6 \mathrm{GHz}$ range. The typical characteristics are high gain of $25 d B$ typical at $100 \mathrm{MHz}$, high IP3: $35 \mathrm{dBm}$ typical and high Pout, P1dB $19 \mathrm{dBm}$ typically. The specific choice of IC is due to its support of wide operative range.

\section{The Receiver}

The receiver consists of identical concurrent dualband antenna; similar as in case of transmitter, a low noise amplifier (LNA), Mixer and a data acquisition system (DAQ). All these subsystems are capable to work simultaneously at the designated frequency bands.

\subsection{The Low Noise Amplifier}

A concurrent dualband LNA is used in this analysis to operate at $2.44 / 5.25 \mathrm{GHz}$. A single pseudomorphic HEMT (p-HEMT) viz. ATF - 36163 is used as an active device. The LNA is comprehended using standard HMIC process with major focus on maximum hardware sharing without any lumped circuitry. Figure 8 shows the fabricated prototype of the LNA [7].

Table 12 summarises the gain characteristics if the LNA. Further, the noise figure (NF) is measured with the help of Agilent noise figure meter setup. Fig. 9 depicts the noise measurement setup for the LNA setup and the plot of simulation and measured NF. 

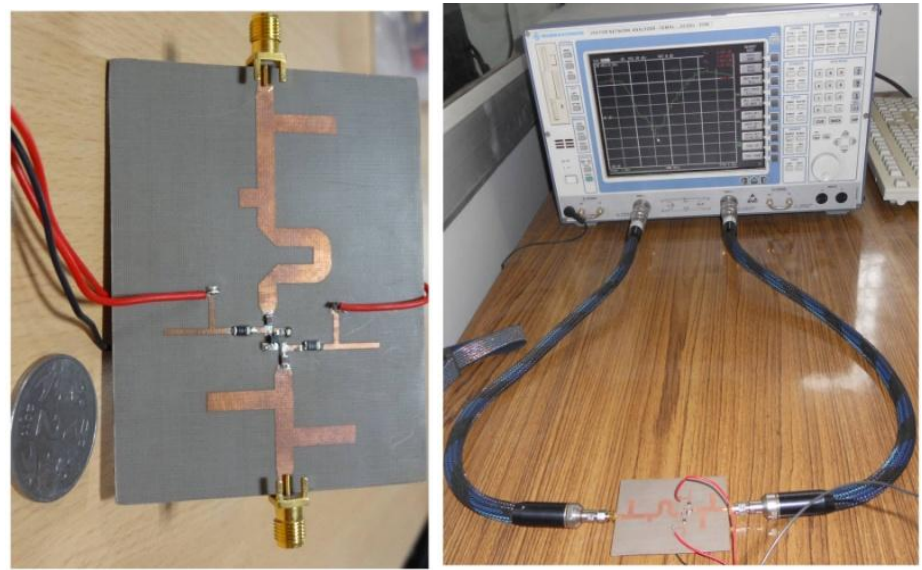

Fig. 8. Fabricated prototype of LNA with measurement setup.
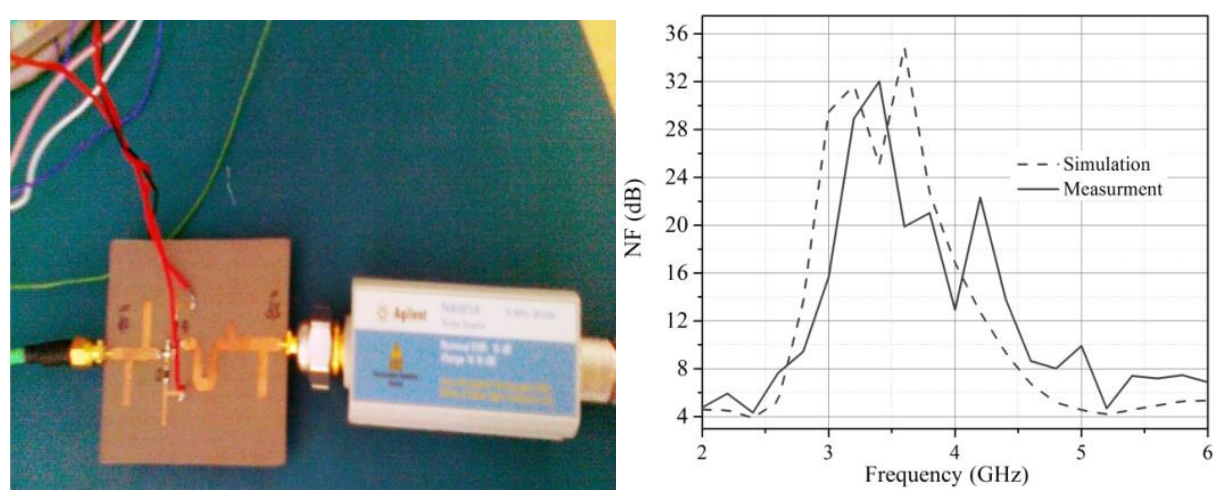

Fig.9. Noise figure measurement setup.

Table 12. Gain Characteristics of the LNA

\begin{tabular}{|c|c|c|c|c|}
\hline \multirow{2}{*}{$\begin{array}{c}\text { Frequency } \\
(\mathrm{GHz})\end{array}$} & \multicolumn{2}{|c|}{$\mathrm{S}_{11}(\mathrm{~dB})$} & \multicolumn{2}{c|}{$\mathrm{S}_{21}(\mathrm{~dB})$} \\
\cline { 2 - 5 } & Simulation & Measurement & Simulation & Measurement \\
\hline 2.44 & -17.24 & -10.54 & 10.11 & 7.16 \\
\hline 5.25 & -13.48 & -15.98 & 6.40 & 7.80 \\
\hline
\end{tabular}

\subsection{The Mixer}

For the purpose of down conversion, two single band mixers from 'Mini circuits' have been used to operate at individual bands. 'ZEM-4300MH' mixer is used at $2.44 \mathrm{GHz}$. It has $8.5 \mathrm{~dB}$ conversion loss and $13 \mathrm{dBm}$ power level. For $5.25 \mathrm{GHz}$, a 'ZMX-7GR' mixer with $8.5 \mathrm{~dB}$ conversion loss and $17 \mathrm{dBm}$ power level has been used. The individual mixers have been fed with the local oscillator frequencies, i.e. $2.44 \mathrm{GHz}$ and 5.25 $\mathrm{GHz}$ to obtain the baseband signal. This baseband signal has been applied to the data acquisition (DAQ) system.

\subsection{The DAQ}

An 'IoTECH DAQ-54' system has been used with a sampling rate of $37 \mathrm{~Hz}$ for digitizing the baseband signal. The digitized baseband signal has been further processed using MATLAB to retrieve the required knowledge from the received signal. 


\section{The System Level Analysis}

The proposed transceiver is further validated on a single substrate with relative dielectric constant of 3.2 and height of 60 mil with a loss tangent of 0.0024 with substrate height of $18 \mu \mathrm{m}$. The sensor is made up of indigenously fabricated concurrent dualband subsystems and some commercial components and laboratory equipment's. Table 13 summarizes the classification of the subsystems used in the proposed transceiver. Fig.10 shows the fabricated prototype of the proposed concurrent dualband RF transceiver for WLAN application.

Table 13. Subsystems of the proposed RF multiband transceiver

\begin{tabular}{|c|l|l|l|}
\hline Sr. No. & \multicolumn{1}{|c|}{ Subsystem } & \multicolumn{1}{|c|}{ Manufacturer } & \multicolumn{1}{|c|}{ Specifications } \\
\hline 1. & Source I \& II & Indigenous Design & $\begin{array}{l}\text { Operation at } 2.44 \mathrm{GHz} \\
\text { and } 5.25 \mathrm{GHz}\end{array}$ \\
\hline 2. & Power Amplifier & Minicircuits & $\begin{array}{l}\text { Operation from DC } \\
(\mathrm{GaLi}-24+) \text { to } 6 \mathrm{GHz}\end{array}$ \\
\hline 3. & WPC/WPD & Indigenous Design & $\begin{array}{l}\text { Concurrent dualband } \\
\text { at 2.44 } \mathrm{GHz} \text { and 5.25 } \mathrm{GHz}\end{array}$ \\
\hline 4. & Antenna & Indigenous Design & $\begin{array}{l}\text { Concurrent dual-band operation } \\
\text { at 2.44 } \mathrm{GHz} \text { and 5.25 } \mathrm{GHz}\end{array}$ \\
\hline 5. & LNA & Indigenous Design & $\begin{array}{l}\text { Concurrent dualband operation } \\
\text { at 2.44 } \mathrm{GHz} \text { and 5.25 } \mathrm{GHz}\end{array}$ \\
\hline 6. & Mixer I \& II IF & Minicircuits & $\begin{array}{l}\text { response from } \\
\text { (SYM-63LH+) DC to } 1000 \mathrm{MHz}\end{array}$ \\
\hline 7. & DAQ-54 & IoTECH & $\begin{array}{l}\text { 22 bit resolution,Input Voltage } \\
-10 \mathrm{~V} \mathrm{DC} \text { to 20 } \mathrm{V} \mathrm{DC}\end{array}$ \\
\hline
\end{tabular}

\subsection{Link Budget Calculation}

The measurements were carried out in indoor conditions with the distance between the antenna and the human subject varying between $0.5 \mathrm{~m}$ and $3 \mathrm{~m}$. The experiment is carried out with three different antenna configurations such as concurrent dualband with a single patch, omni-directional patch antenna array and a direction patch antenna array. The transmitter and receiver losses are estimated by considering the contribution of individual subsystem, in terms of its gain or NF, in the transceiver. The estimation of link budget is calculated by using Eq. 2. Table 14 gives the detail parametric analysis data in each of these cases.

$$
P_{R X}=P_{T X}+G_{T X}-L_{T X}-L_{F S}+G_{R X}-L_{R X}
$$

Where where $P T X=$ Transmitted output power in $d B m, G T X=$ Transmitter antenna gain in $d B i, L T X=$ Transmitter losses in $d B, L F S=$ Free space losses in $d B, G R X=$ Receiver antenna gain in $d B i, L R X=$ Receiver losses in $d B$.

\subsection{Link Margin Calculation}

To ensure proper working of the proposed multiband transceiver, its sensitivity analysis is very important. Fig. 10 shows the block diagram of the RF section of the proposed transceiver for sensitivity analysis. The diagram depicts the individual subsystems gain and NF contribution. With this measurement setup, it is observed that the signal strength at the receiver end decreases considerably with the distance. The sensitivity analysis is carried out for a bandwidth of $3 \mathrm{~Hz}$.

Table 15 provides the performance of the proposed transceiver under different measurement conditions. With an output SNR of value as high as $20 d B$, detection of very weak signals is guaranteed. The link margin of the proposed transceiver attain a minimum value of $74 \mathrm{~dB}$ with the help of a single patch antenna. This indicates that the proposed transceiver can detect the target accurately at considerable distance if the required link budget is less than $74 d B$. 


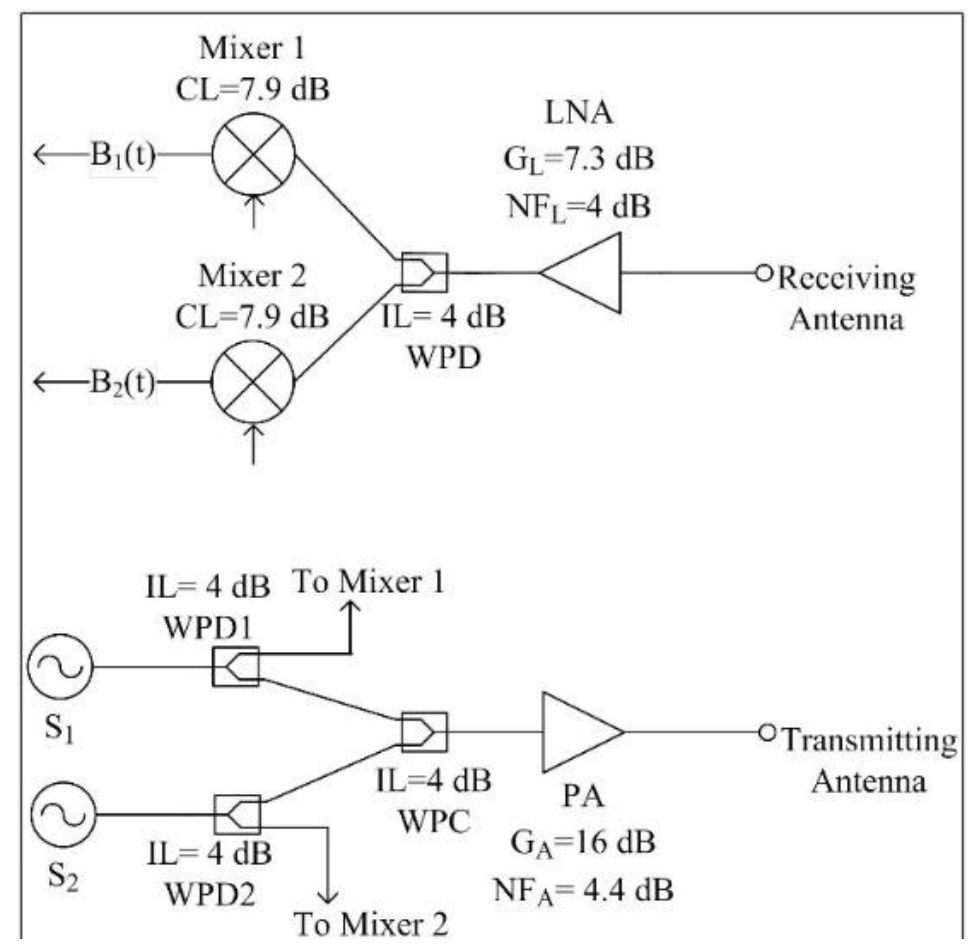

Fig. 10. Block diagram of RF section of the proposed transceiver for sensitivity analysis.

\subsection{Detection Range Analysis}

The range of detection for the proposed transceiver is estimated with the help of the Radar range equation.

$$
P_{R}=P_{T}\left[A \frac{G_{T} G_{R}}{4 \pi}\left(\frac{\lambda}{4 \pi R^{2}}\right)\right]
$$

Here, $P T=10 \mathrm{~dB}, \lambda=0.078 \mathrm{~m}$ and Radar cross section $(\sigma)=0.01$ [129]. The range is estimated with different antenna configurations. Substituting the gain $(G)$ values in Eq. 3, the maximum distance of detection under free space condition and without any obstacle was calculated. Table 16 summarizes the detection range for the proposed sensor. The range may be further increased by using high gain antenna and LNA in the design architecture.

Table:14. Link budget performance of the proposed NIVSD sensor

\begin{tabular}{|c|c|c|c|c|}
\hline \multicolumn{2}{|l|}{ Parameter } & $\begin{array}{l}\text { Antenna array } \\
\text { (Directive) }\end{array}$ & $\begin{array}{l}\text { Antenna array } \\
\text { (Omni-directive) }\end{array}$ & $\begin{array}{l}\text { Single } \\
\text { patch }\end{array}$ \\
\hline \multicolumn{2}{|c|}{ Antenna Gain $(d B i)$} & 7.5 & 5.5 & 2.5 \\
\hline \multicolumn{2}{|c|}{ Transmitter losses $(\mathrm{dBm})$} & \multicolumn{3}{|c|}{10.41} \\
\hline \multicolumn{2}{|c|}{ Receiver losses $(d B m)$} & \multicolumn{3}{|c|}{8.81} \\
\hline \multirow{4}{*}{$\begin{array}{l}\text { Path } \\
\operatorname{loss}(\mathrm{dBm})\end{array}$} & at $0.5 \mathrm{~m}$ & \multicolumn{3}{|c|}{44.13} \\
\hline & at $1 \mathrm{~m}$ & \multicolumn{3}{|c|}{50.15} \\
\hline & at $2 \mathrm{~m}$ & \multicolumn{3}{|c|}{56.17} \\
\hline & at $3 \mathrm{~m}$ & \multicolumn{3}{|c|}{59.70} \\
\hline \multirow{4}{*}{$\begin{array}{l}\text { Link } \\
\text { budget }(\mathrm{dBm})\end{array}$} & at $0.5 \mathrm{~m}$ & -38.35 & -42.35 & -49.05 \\
\hline & at $1 \mathrm{~m}$ & -44.37 & -48.37 & -55.07 \\
\hline & at $2 \mathrm{~m}$ & -50.39 & -54.39 & -61.09 \\
\hline & at $3 \mathrm{~m}$ & -53.92 & -57.92 & -64.62 \\
\hline
\end{tabular}


Table:15. Link margin performance of the proposed NIVSD sensor

\begin{tabular}{|c|c|c|c|c|}
\hline \multicolumn{2}{|l|}{ Parameter } & $\begin{array}{l}\text { Antenna array } \\
\text { (Directive) }\end{array}$ & $\begin{array}{l}\text { Antenna array } \\
\text { (Omni-directive) }\end{array}$ & $\begin{array}{l}\text { Single } \\
\text { patch }\end{array}$ \\
\hline \multicolumn{2}{|l|}{ Thermal noise } & \multicolumn{3}{|c|}{$-174 \mathrm{dBm} / \mathrm{Hz}$} \\
\hline \multicolumn{2}{|l|}{ SNR } & \multicolumn{3}{|c|}{$20 d B$} \\
\hline \multicolumn{2}{|l|}{ Sensitivity } & \multicolumn{3}{|c|}{$-138.62 \mathrm{dBm}$} \\
\hline \multirow{4}{*}{$\begin{array}{l}\text { Link } \\
\text { budget }(\mathrm{dBm})\end{array}$} & at $0.5 \mathrm{~m}$ & -38.35 & -42.35 & -49.05 \\
\hline & at $1 \mathrm{~m}$ & -44.37 & -48.37 & -55.07 \\
\hline & at $2 \mathrm{~m}$ & -50.39 & -54.39 & -61.09 \\
\hline & at $3 \mathrm{~m}$ & -53.92 & -57.92 & -64.62 \\
\hline \multirow{4}{*}{$\begin{array}{l}\text { Link Margin } \\
(d B m)\end{array}$} & at $0.5 \mathrm{~m}$ & 100.27 & 96.27 & 89.57 \\
\hline & at $1 \mathrm{~m}$ & 94.25 & 90.25 & 83.55 \\
\hline & at $2 \mathrm{~m}$ & 88.23 & 84.23 & 77.53 \\
\hline & at $3 \mathrm{~m}$ & 84.70 & 80.70 & 74 \\
\hline
\end{tabular}

Table 16: Detection range of the proposed sensor

\begin{tabular}{|l|l|l|}
\hline Antenna Configuration & Gain $(\mathrm{dBi})$ & $\begin{array}{l}\text { Detection Range } \\
\text { (meters) }\end{array}$ \\
\hline Concurrent dualband Single Patch & 2.3 & 2.8 \\
\hline Concurrent Dualband Omnidirectional array & 5.5 & 4 \\
\hline Concurrent Dualband Directional array & 7.5 & 5 \\
\hline
\end{tabular}

\subsection{Safety Factor Analysis}

For an RF transceiver to be deployed in the field, the level of electromagnetic radiation (EMR) to which the human operators or users may get expose during the measurements is a crucial factor in the adaptation of the transceiver and its design. For the proposed transceiver, the RF level at various level is estimated. Table 17 summarizes the safety factor analysis with different types of antenna. It is evident from the values tabulated in Table 17 that this sensor is safe enough to be used since the amount of EMR is quite small and will never turn out to be hazardous to the human users when deployed commercially. The safety factor is estimated by using the Eq.4.

$$
S\left(W / m^{2}\right)=\left[\frac{P_{T} G_{T}}{4 \pi L^{2}}\right]
$$

where $P T=$ Radiating power in $d B m, G T=$ Antenna gain in $d B i, L=$ Distance between the antenna and the obstacle in meters.

Table 17: Safety factor analysis*

\begin{tabular}{|l|c|c|c|}
\hline \multirow{2}{*}{$\begin{array}{l}\text { Distance } \\
(\mathrm{Lm})\end{array}$} & \begin{tabular}{l}
$|c|$ \\
\cline { 2 - 4 } \\
patch antenna
\end{tabular} & $\begin{array}{l}\text { Safety factor(in W/m } \mathrm{m}^{2} \text { ) } \\
\text { directional patch antenna }\end{array}$ & $\begin{array}{l}\text { Concurrent dualband } \\
\text { directive patch antenna }\end{array}$ \\
\hline 0.5 & $1.78 \times 10^{-5}$ & $1.11 \times 10^{-5}$ & $5.41 \times 10^{-6}$ \\
\hline 1 & $4.45 \times 10^{-6}$ & $2.78 \times 10^{-6}$ & $1.35 \times 10^{-6}$ \\
\hline 2 & $1.11 \times 10^{-6}$ & $6.95 \times 10^{-7}$ & $3.37 \times 10^{-7}$ \\
\hline 3 & $4.49 \times 10^{-7}$ & $3.08 \times 10^{-7}$ & $1.5 \times 10^{-7}$ \\
\hline
\end{tabular}




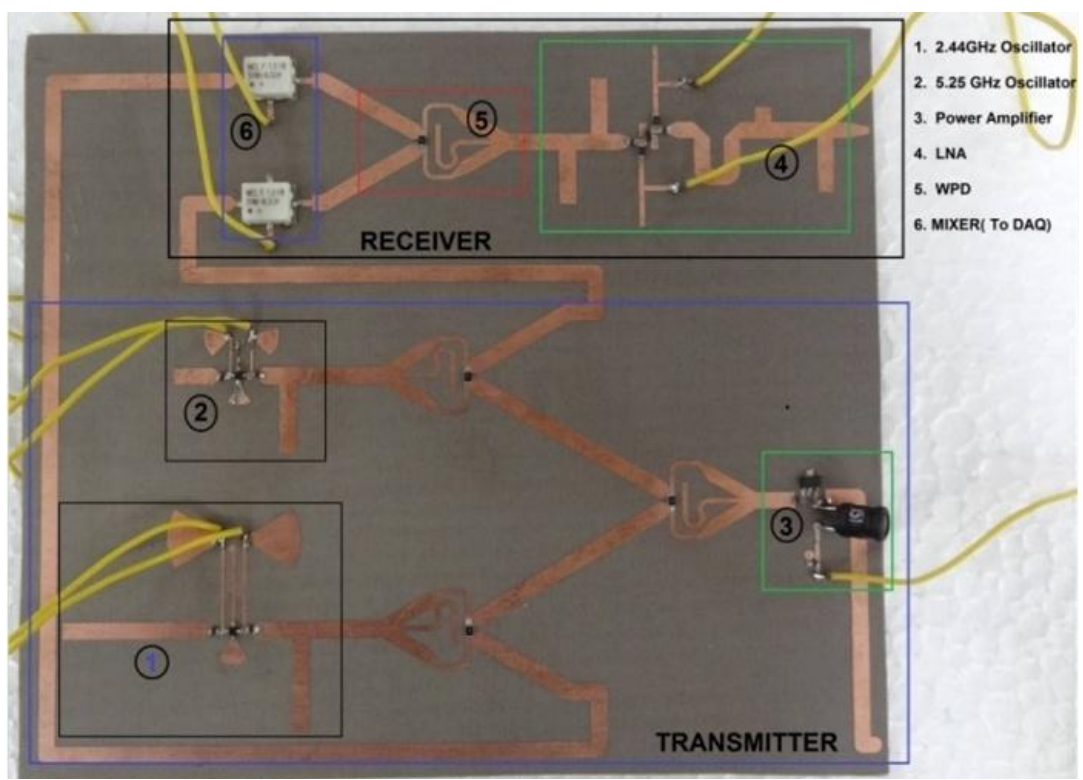

(a)

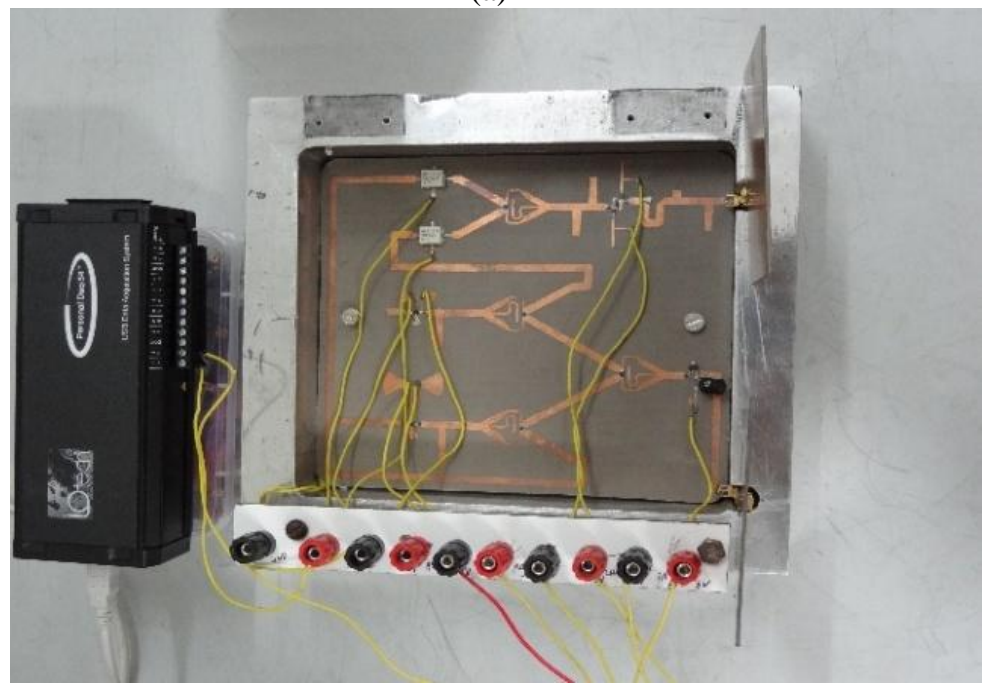

(b)

Figure 11: Characterization of the proposed concurrent dualband RF transceiver (a) Fabricated PCB prototype (b) Prototype with casing.

Table 18: Qualitative Analysis

\begin{tabular}{|c|c|c|c|c|c|}
\hline Contributions & $\begin{array}{l}\text { Operation } \\
\text { band }\end{array}$ & $\begin{array}{l}\text { Concurrent } \\
\text { operation }\end{array}$ & $\begin{array}{l}\text { Design of } \\
\text { subsystems }\end{array}$ & $\begin{array}{c}\text { Transceiver } \\
\text { operation }\end{array}$ & Technology \\
\hline Sharma et. al.[8] & $\begin{array}{c}2.4 \text { and } 5.2 \\
\mathrm{GHz}\end{array}$ & Yes & $\begin{array}{l}\text { Off the shelf } \\
\text { laboratory } \\
\text { equipment }\end{array}$ & No & -- \\
\hline Akhtar and Pathak [9] & $\begin{array}{l}2.4 \text { and } \\
5.2 \mathrm{GHz}\end{array}$ & Yes & $\begin{array}{l}\text { Off the shelf } \\
\text { laboratory } \\
\text { equipment }\end{array}$ & No & HMIC \\
\hline A. Behzad et.al.[10] & $\begin{array}{c}2.4 \text { and 5-6 } \\
\mathrm{GHz}\end{array}$ & Yes & - & No & COMS \\
\hline Present work & $\begin{array}{c}2.44 \text { and } 5.25 \\
\text { GHz }\end{array}$ & Yes & Indigenous & Yes & HMIC \\
\hline
\end{tabular}




\section{Conclusions}

In this paper, a concurrent dualband RF transceiver is proposed and demonstrated. The proposed transceiver is devised for simultaneous operation over two frequency bands, namely $2.44 \mathrm{GHz}$ and $5.25 \mathrm{GHz}$ band. The proposed system bridge the trade-off between lower noise content and higher detection accuracy; which was unattended before the initiation of this work. The fabricated prototype demonstrated a fair working with its sensitivity analysis. Link margin and link budget are used as the cost function for the sensitivity analysis. The fabricated prototype demonstrated a link budget of $-64 \mathrm{dBm}$ and link margin of $74 \mathrm{dBm}$.

Further, the implemented transceiver exhibits an EMR of $1.5 \times 10^{-7}$ for concurrent dual-standard WLAN application. Hence, the proposed transceiver is efficient as well as safe for the human operation. In future, the proposed system can be converted into a reconfigurable system to achieve adaptable operation.

\section{References}

[1] B. Razavi, "Challenges in Portable RF Transceiver Design," IEEE Circuits and Devices Magazine, vol. 12, no. 5, pp. 12-25, Sep 1996.

[2] A. Rathore, R. Nilavalan, A. Tarboush and T. Peter, "Compact Dual-Band (2.4/5.2GHz) Monopole Antenna for WLAN Applications," International Workshop on Antenna Technology (iWAT), Mar 2010, pp. 1-4.

[3] B. Iyer, N.P. Pathak and D. Ghosh, "Concurrent Dualband Patch Antenna Array for Non-Invasive Human Vital Sign Detection Application", IEEE Asia-Pacific Conference on Applied Electromagnetics(APACE-14),Johor Bahru, Malaysia,Dec.2014, pp.150-153.

[4] B. Iyer, A. Kumar and N.P. Pathak, "Design and Analysis of Subsystems for Concurrent Dual-band Transceiver for WLAN Applications", International Conference on Signal Processing and Communication (ICSC-13), Noida-India, Dec.2014, pp.57-61.

[5] K. Cheng and F. Wong, "A New Wilkinson Power Divider Design for Dual Band Application," IEEE Microwave and Wireless Component Letters, vol. 17, pp. 664-666, Sept. 2007.

[6] Y. Cassivi and $\mathrm{Ke} \mathrm{Wu,} \mathrm{"Low} \mathrm{cost} \mathrm{microwave} \mathrm{oscillator} \mathrm{using} \mathrm{substrate} \mathrm{integrated} \mathrm{waveguide} \mathrm{cavity",}$ IEEE Microwave and Wireless Components Letters, vol. 13, no. 2, pp. 48-50, Feb. 2003.

[7] Brijesh Iyer and N. P. Pathak, "Concurrent dualband LNA for non-invasive vital sign detection", Microwave and Optical Technology Letters, vol. 56, no.2, pp. 391-394, Feb. 2014.

[8] Vivek Sharma, Zubair Akhter, and Nagendra P. Pathak, "2.4/5.2 GHz Concurrent Dual Band Local Area Network Transmitter”, Journal of Low Power Electronics, Vol. 8, pp. 1-7, 2012.

[9] Zubair Akhter, and Nagendra P. Pathak, "Concurrent Dual Band Transmitter for 2.4/5.2GHz Wireless LAN Applications, 2011 International Symposium on Electronic System Design (ISED), Dec. 2011,pp.1-5.

[10] S. Andersson et.al, "Multiband direct RF-sampling receiver front-end for WLAN in $0.13 \mu \mathrm{m}$ CMOS", $18^{\text {th }}$ European Conference on Circuit Theory and Design (ECCTD 2007), Aug.2007, pp.168 - 171. 